\title{
$\underline{\text { Abnormal regulation of fibronectin production by fibroblasts in psoriasis }}$
}

Barbara Gubán ${ }^{1}$, Krisztina Vas ${ }^{1}$, Zsanett Balog ${ }^{1}$, Máté Manczinger ${ }^{1}$, Attila Bebes ${ }^{1}$, Gergely Groma $^{2}$, Márta Széll ${ }^{2,3}$, Lajos Kemény ${ }^{1,2}$, Zsuzsanna Bata-Csörgö ${ }^{1,2}$

${ }^{1}$ Department of Dermatology and Allergology, University of Szeged, Szeged, Hungary

${ }^{2}$ MTA-SZTE Dermatological Research Group, University of Szeged, Szeged, Hungary

${ }^{3}$ Department of Medical Genetics, University of Szeged, Szeged, Hungary

\section{Corresponding author:}

Barbara Gubán, Department of Dermatology and Allergology, University of Szeged,

Korányi fasor 6, H-6720 Szeged, HUNGARY; Email: gubanbarbi@gmail.com

Tel: +36-62-546402; Fax: +36-62-545954

\section{Short title: Abnormal fibronectin regulation in psoriasis}

Manuscript word: 2975

Table count: 0

Figure count: 6

Supplementary table: 2

Supplementary figure: 4

Supplementary materials and methods: 1

\section{Conflict of interest}

The authors state no conflict of interest. 
What's already known about this topic?

- In psoriasis the non-lesional skin already contains abnormalities as base for the manifestation of the disease.

- Fibronectin and its splice variant $\operatorname{EDA}^{+} \mathrm{FN}$ are essential extracellular matrix proteins influencing major cellular processes and they are abnormally expressed in psoriatic skin.

- KGF is overexpressed in psoriatic lesional skin and contribute to keratinocyte hyperproliferation.

What does this study add?

- KGF and its receptor, FGFR2 is overexpressed in the psoriatic non-lesional skin.

- KGF in an autocrine manner influences the regulation $\mathrm{EDA}^{+} \mathrm{FN}$ production in fibroblasts through MEK1 signaling.

- Fibroblasts express the FGFR2-IIIc splice variant of FGFR2 receptor.

- STAT1 negatively regulates $\mathrm{FN}$ and $\mathrm{EDA}^{+} \mathrm{FN}$ production in normal cultured fibroblasts, but not in fibroblasts, derived from psoriatic non-lesional skin.

- STAT1 is active in healthy skin and psoriatic lesional skin, but not in non-lesional psoriatic skin. 


\section{Summary}

Background Data indicate that in psoriasis abnormalities are already present in the nonlesional skin. TGF $\beta$, KGF together with fibronectin and $\alpha 5 \beta 1$ integrin was suggested to play a crucial role in the pathogenesis of psoriasis by influencing inflammation and keratinocyte hyperproliferation.

Objectives To investigate the expression of KGF, FGFR2, fibronectin (FN) and EDA ${ }^{+} \mathrm{FN}$ in healthy and non-lesional psoriatic skin and to study the effect of KGF on the regulation of FN and $\mathrm{EDA}^{+} \mathrm{FN}$ production by fibroblasts.

Methods Healthy, non-lesional psoriatic skin and lesional psoriatic skin were immmunostained for $\alpha 5$ integrin, KGF, FGFR2, $\mathrm{EDA}^{+} \mathrm{FN}$ and STAT1. KGF treated cell cultures were analyzed for FN and $\mathrm{EDA}^{+} \mathrm{FN}$ mRNA and protein by real-time RT-PCR and flow cytometry respectively. The four major downstream signaling of KGF was investigated by blocking experiments using MEK1, AKT1/2, STAT1 and STAT3 inhibitors.

Results The expression of $\alpha 5$ integrin, $\mathrm{EDA}^{+} \mathrm{FN}, \mathrm{KGF}$ and its receptor FGFR2 is elevated in psoriatic non-lesional skin compared to healthy skin. KGF mildly induced EDA ${ }^{+} F N$, but not FN expression in healthy fibroblasts through MAPK signaling. Fibroblasts express the FGFR2-IIIc. STAT1 negatively regulates both $\mathrm{FN}$ and $\mathrm{EDA}^{+} \mathrm{FN}$ expressions in healthy fibroblasts and this regulation is compromised in fibroblasts derived from non-lesional psoriatic dermis. We detected active STAT1 in healthy and lesional skin, similar to a previous report, however, in the non-lesional skin STAT1 activation was absent in tissues far away from lesions.

Conclusions The production of FN, $\mathrm{EDA}^{+} \mathrm{FN}$ by fibroblasts and the signaling of STAT1 is abnormally regulated in the psoriatic non-lesional skin. 


\section{Introduction}

It is well stated that psoriasis is an inflammatory skin disease in which both innate and adaptive immune activation play an essential role in the maintenance of the abnormal skin phenotype ${ }^{1}$. However, it is less known how much resident cells of the tissue contribute to the pathology. A reasonable approach to seek for alterations in tissue responses in psoriasis is to investigate the phenotypically normal looking non-lesional (NL) psoriatic skin. The main fibronectin receptor $\alpha_{5} \beta_{1}$ integrin was found to be overexpressed in the NL psoriatic epidermis relative to normal ${ }^{2,3}$. There is evidence that proper regulation of integrin expression in keratinocytes is essential for normal epidermal homeostasis as shown by the suprabasal overexpression of integrins in transgenic mice resulting in epidermal hyperproliferation and inflammatory reaction ${ }^{4}$. In the steady state of normal human adult epidermis $\alpha_{5}$ integrin expression of keratinocytes is downregulated. A possible explanation of $\alpha_{5}$ integrin overexpression in NL skin is the presence of fibronectin (FN) and one of its isoforms, the extra-domain-A containing fibronectin $\left(\mathrm{EDA}^{+} \mathrm{FN}\right)$, in the microenvironment of basal keratinocytes ${ }^{3,5}$. Keratinocyte growth factor (KGF/FGF7) is a member of the fibroblast growth factor (FGF) family produced by mesenchymal cells and considered to be a major growth factor for keratinocytes. Several reports suggest that KGF reduces the ability of keratinocytes to initiate terminal differentiation and undergo programmed cell death. Overexpression of KGF in the basal epidermal cell layer of transgenic mice results in epidermal hyperplasia ${ }^{6}$. There is also evidence suggesting that fibroblasts from L and NL skin of psoriatic patients induce keratinocyte outgrowth by producing soluble signals ${ }^{7}$. More recently, it has been reported that KGF can induce the expression of $\alpha_{5}$ integrin and delays the expression of keratin 10 and transglutaminase in keratinocytes ${ }^{8}$. Indirect evidence, such as measurement of mitogenic activity, suggests that the specific receptor for KGF on epithelial cells is the IIIb splice variant of fibroblast growth factor receptor 2 (FGFR2) ${ }^{9}$.

According to our observations, psoriatic NL skin displays a marked overexpression of KGF, FGFR2, $\alpha_{5}$ integrin and $\mathrm{EDA}^{+} \mathrm{FN}$ compared to healthy skin, therefore in this study we focused on investigating regulatory mechanisms involving KGF and fibronectin. Our results revealed that $\mathrm{KGF}$ regulate $\mathrm{EDA}^{+} \mathrm{FN}$ production in an autocrine manner through MAPK signaling in healthy fibroblasts. With these results we designed an in silico model to predict a possible regulatory network for the effect of $\mathrm{KGF}$ on $\mathrm{EDA}^{+} \mathrm{FN}$ production. We provide in vitro evidence that both FN and $\mathrm{EDA}^{+} \mathrm{FN}$ are negatively regulated by activated STAT1 in healthy fibroblasts, and this is in contrast to psoriatic NL skin-derived fibroblasts. Active, 
phosphorylated STAT1 was found in healthy skin as well as in psoriatic lesions, but not in psoriatic NL skin, suggesting a crucial mechanism for keeping NL skin in a preactivated state for developing a chronic wound healing phenotype. 


\section{Materials and methods}

\section{Skin biopsies}

Patients with moderate-to-severe chronic plaque type psoriasis and healthy volunteers (age 18-60 years) were enrolled into the study. Patients had a medication-free period of at least 4 weeks of systemic and/or at least 2 weeks without local therapy. Participant informed consent was obtained prior surgical intervention. PASI score was determined for all patients by dermatologists. Samples were collected from 16 patients and 25 healthy volunteers for the experiments. Mechanical stress was induced by tape stripping procedure, and then punch biopsies were taken from uninvolved skin of psoriatic patients $(n=6)$ and from healthy $(n=6)$ subjects from tape stripped and non-treated (control) skin area from the buttock area at 24 and 48 hours after treatment (supplementary figure 1) for all other experiments tissues without the introduction of mechanical stress were used. All tissue collection complied with the Guidelines of the Helsinki Declaration and was approved by the Regional and Institutional Research Ethics Committee (2799, 3517).

\section{Immunofluorescent staining}

Human punch biopsies were frozen embedded, stored at $-80^{\circ} \mathrm{C}$, then cut into $6 \mu \mathrm{m}$ sections. Samples were fixed in Fixation/Permeabilization Concentrate and Diluent (eBioscience, San Diego, CA) and resuspended in PBS. The sections were incubated for $30 \mathrm{~min}$ in goat serum (Sigma-Aldrich, St. Louis, MO, USA). The following primary antibodies were used: FGFR2 (1:100, Bek (C-17), Santa Cruz Biotechnology, Santa Cruz, CA), KGF (1:500, FGF-7 (N-14), Santa Cruz Biotechnology), $\alpha_{5}$ integrin (1:200, Becton-Dickinson, Franklin Lakes, NJ, USA), EDA $^{+}$FN (1:500, clone IST9, Abcam, Cambridge, UK), and p-STAT1(Ser727), p-STAT1 (Tyr701), (both 1:400, Cell Signaling Technology, Beverly, MA) overnight at $4^{\circ} \mathrm{C}$. Goat antirabbit IgG-Alexa Fluor 488, donkey anti-goat IgG-Alexa Fluor 546, goat anti-mouse IgGAlexa Fluor 647 and Alexa Fluor 546 were used as secondary antibodies (all 1:500, from Life Technologies, Carlsbad, CA) for $2 \mathrm{~h}$, at room temperature. Sections were incubated without the primary antibody or with isotype control antibody for negative staining controls. Nuclei were stained with DAPI (Sigma-Aldrich).

Cultured human fibroblasts, keratinocytes and $\mathrm{HaCaT}$ cells were collected after brief trypsinization ( $0.25 \%$ trypsin solution, Sigma Aldrich) and centrifuged onto a slide using a 
cytocentrifuge (Cytopro $^{\mathrm{TM}}$, Wescor, Logan, UT, USA), then fixed in $2 \%$ paraformaldehyde (Sigma-Aldrich). Stainings were carried out, as described above. Images were documented with a Zeiss AxioImager Z1 fluorescence microscope (Carl Zeiss Microscopy GmbH, Munich, Germany) equipped with an AxioCam MRm camera. Image processing and data analysis were conducted using ZEN 2012 Microscope and Imaging or ImageJ software.

\section{Flow cytometry}

Cells were harvested as described, above fixed in Fixation/Permeabilization Concentrate and Diluent (eBioscience) and resuspended in PBS. Primary antibodies anti-EDA ${ }^{+} F N$ (1:500, clone IST9, Abcam), anti-FN (1:1000, clone IST4, Sigma-Aldrich) were applied for $45 \mathrm{~min}$. Mouse IgG1 isotype antibody (Sigma-Aldrich) was used, for negative as control. Cells were then washed in PBS, and incubated with secondary antibodies as described above. Samples were analysed on a FACS Calibur flow cytometer equipped with 488 and $633 \mathrm{~nm}$ lasers (Becton-Dickinson).

\section{Statistical analysis}

For statistical analysis, Repeated Measures Friedman ANOVA, Wilcoxon or one-way ANOVA were used. Multiple comparisons were done with SigmaPlot software (Systat Software, Inc., Chicago, IL, USA). A probability test was used to test for normality, $\mathrm{P} \leq 0.05$ was considered significant.

Detailed information of the materials and methods regarding cell culture experiments, RT qRT-PCRs and the description of the in silico model are presented as supplement (Supplementary materials and methods). 


\section{Results}

Altered protein expression of $\alpha_{5}$ integrin, $\mathrm{EDA}^{+} \mathrm{FN}$, KGF and FGFR2 in psoriatic nonlesional skin

Healthy skin and psoriatic NL skin were investigated for differences in the expressions of $\alpha_{5}$ integrin, $\mathrm{EDA}^{+} \mathrm{FN}, \mathrm{KGF}$ and FGFR2 before and 24, 48 hours after tape stripping. Immunofluorescent staining revealed a striking difference in all protein expressions examined even without tape stripping between normal and psoriatic non-lesional skin (Fig. 1). Mild mechanical stress introduced by tape stripping of the skin did not lead to any obvious changes in $\alpha_{5}$ integrin, $\mathrm{EDA}^{+} \mathrm{FN}, \mathrm{KGF}$ and FGFR2 expressions or distributions at 24 and 48 hours after treatment in NL skin. In healthy control sections a slight increase in all protein expression was observed based on immunostaining (Fig. S1a-d; see Supporting Information).

\section{KGF treatment of healthy human fibroblasts leads to the elevation of $\operatorname{EDA}^{+} \mathrm{FN}$ production}

$\mathrm{EDA}^{+} \mathrm{FN}$ and $\mathrm{KGF}$ are known to stimulate keratinocyte proliferation. KGF induces the expression of the major FN cell surface receptor $\alpha_{5} \beta_{1}$ integrin. Given the differences in $\mathrm{EDA}^{+} \mathrm{FN}$ and KGF protein levels in healthy and NL psoriatic skin, we set out to investigate a putative regulatory connection between these two molecules. Exogenous treatment of cultured healthy fibroblasts with KGF for 24 hours increased the level of the $\mathrm{EDA}^{+} \mathrm{FN}$ splice variant, but not the total FN protein based on immunostaining and flow cytometry measurements (Fig. $2 \mathrm{a}, \mathrm{b})$. A similar increase in the $\mathrm{EDA}^{+} \mathrm{FN}$ mRNA splice variant was detected, while the total FN mRNA remained unchanged (Fig. 2c). We also investigated this effect of KGF on normal human keratinocytes and melanocytes and on the keratinocyte cell line, HaCaT. As expected, keratinocytes and HaCaT cells expressed the FN and the $\mathrm{EDA}^{+} \mathrm{FN}$ at a very low level compared to fibroblasts, while melanocytes expressed both proteins at a comparable level to fibroblasts (Fig. S3). However, upon in vitro KGF treatment these cells did not display detectable changes in mRNA and protein expressions of $\mathrm{EDA}^{+} \mathrm{FN}$ and total FN (Fig. S2a-c; see Supporting Information).

\section{Expression of FGFR2 splice variants in fibroblasts, melanocytes and keratinocytes}

Two splice variants have been identified for FGFR2 designated as FGFR2-IIIb and FGFR2IIIc that have different ligand binding preferences. These result were based on mitotic activity 
measurements ${ }^{16}$. KGF has been shown to act on the FGFR2-IIIb variant increasing cellular proliferation ${ }^{17}$. We determined the expression of the splice variants on healthy fibroblasts, melanocytes and keratinocytes using specific primers designed for RT-PCR, revealing that melanocytes and keratinocytes expressed the FGFR2-IIIb only, while fibroblasts mainly expressed the FGFR2-IIIc variant (Fig. 3a, b).

\section{MAPK signaling is involved in the regulation of $\mathrm{EDA}^{+} \mathrm{FN}$ by KGF in healthy fibroblasts}

FGF signals (including KGF) are coordinated by four major pathways: the RAS-RAF-MAPK, the PI3-AKT, the STAT and the PLC $\gamma$ signaling ${ }^{18,19}$. In order to get a better insight into the modulation of FN expression by KGF in cultured fibroblasts derived from healthy skin, we performed blocking experiments targeting key molecules of the signal transduction pathways using specific inhibitors available for MEK1 (MAPK), Akt1/2 (PI3-Akt), STAT1 and STAT3 (STAT) either alone or in combination. After $24 \mathrm{~h}$ of inhibitory treatment the expressions of FN and EDA $^{+}$FN was determined by flow cytometry and RT-PCR. The KGF induced $\mathrm{EDA}^{+} \mathrm{FN}$ elevation was abolished by the inhibition of MEK1 and returned to the level of control fibroblasts (Fig. 4a). In contrast, blocking Akt1/2 did not have an effect on $\mathrm{EDA}^{+} \mathrm{FN}$ protein expression (Fig. S4; see Supporting Information). The inhibition of STAT1 or STAT3 did not influence KGF-mediated changes in $\mathrm{EDA}^{+} \mathrm{FN}$ levels (Fig. 4b), however, impairing these signaling molecules resulted in a KGF independent elevation of both FN and $\mathrm{EDA}^{+} \mathrm{FN}$ protein levels that was significant in the case of STAT1 inhibition (Fig. 4c).

\section{Abnormal STAT1 activation in psoriatic skin plays a role in the regulation of both $\mathrm{FN}$ and $\operatorname{EDA}^{+} \mathbf{F N}$}

To investigate further, we compared the $\mathrm{FN}$ and $\mathrm{EDA}^{+} \mathrm{FN}$ expressions between healthy and psoriatic NL skin derived fibroblasts 24 hours after STAT1 or STAT3 inhibition in culture. Changes upon STAT3 impairment were not significant, however, blockade of STAT1 did not lead to the elevation of total FN and the $\mathrm{EDA}^{+} \mathrm{FN}$ splice variant in fibroblasts from NL skin in contrast to healthy controls (Fig. 4c). Therefore, we investigated the phosphorylation pattern of STAT1 at Tyr701 and Ser727 positions that are known to be key amino acid modifications leading to dimerization and influencing activity. Immunofluorescent staining for the phosphorylated Ser727 was highest in lesional psoriatic skin, lower, but clearly detectable in healthy skin whereas NL skin samples showed the lowest intensity. In two out of four investigated NL samples phosphorylation was undetectable (Fig. 4d). Staining for the phosphorylated Tyr701 showed a much less noticeable but similar pattern. In samples of 
patients where no serine phosphorylation was detected in the NL skin, the staining for the phosphorylated Tyr701 was also not visible in either NL or L areas. To elucidate whether differences observed in STAT1 activity among patients correlated with the severity of the disease, PASI scores of donor patients were compared. The patients whose NL skin was negative for phosphorylations of STAT1 had a lower PASI score (12.4 and 17.8), therefore we were able to take NL samples further away from lesions at least $10 \mathrm{~cm}$ distance whereas patients with detectable, but low STAT1 activity in NL skin had a higher PASI score (19.6 and 20).

\section{In silico model construction}

We constructed an in silico model based on our in vitro results involving KGF- and FNsignaling and the resultant transcriptional regulation network (Fig. 5, Table S1-2). Our data already suggested the participation of MAPK signaling in KGF induced fibronectin splicing. The generated co-expression matrix implied a potential role of peptidyl-prolyl cis-trans isomerase (PPIG), a protein important in both protein folding and splicing ${ }^{20}$, which is regulated by MEK1 induced AP-1. Changes in MEK1 activity could lead to the modulation of fibronectin splicing through PPIG resulting in elevated $\mathrm{EDA}^{+} \mathrm{FN}$ level. Our model also indicated that STAT3 negatively regulates the expression of MEK1. This suggested inhibitory effect of STAT3 on MEK1 may account for the increased EDA ${ }^{+}$FN production upon STAT inhibition. However, our model did not explain our data on the significant increase in $\mathrm{EDA}^{+} \mathrm{FN}$ and FN following STAT1 inhibition in normal fibroblasts. The schematic summary model of KGF induced changes on fibronectin based on our results (in vivo, in vitro and in silico) of normal skin is presented in Figure 6. 


\section{Discussion}

One of the major characteristics of psoriatic lesional skin is the hyperproliferation of keratinocytes, where KGF is known to play an important role. At the protein level both KGF and FGFR2 were demonstrated to be elevated in lesional skin compared to normal skin ${ }^{21}$. At the mRNA level in non-lesional as well as in lesional tissue an increased expression for both KGF and FGFR2 transcripts were also described by others ${ }^{21,22}$. KGF stimulates keratinocyte proliferation and it influences terminal differentiation ${ }^{6,23}$. The only known source of KGF in the skin are fibroblasts, and keratinocytes can mediate KGF production in fibroblasts through IL-1 ${ }^{24,25}$, establishing a double paracrine regulatory loop, controlled by AP-1 subunits c-Jun and $\mathrm{JunB}$, and directing the regeneration of the epidermis and maintaining tissue homeostasis in the $\mathrm{skin}^{26}$. It was reported that micro RNA miR-125 is downregulated in psoriatic lesional tissue. miR-125 is known to have a negative influence on keratinocyte proliferation, partially by downregulating FGFR2 expression and driving keratinocytes towards differentiation ${ }^{27}$.

Integrins and their corresponding extracellular ligands also influence cell proliferation and differentiation ${ }^{28}$. Overexpression of $\alpha 5$ integrin and $\mathrm{EDA}^{+} \mathrm{FN}$ has already been reported in connection with psoriasis and our group demonstrated that one of the potential sources of $\mathrm{EDA}^{+} \mathrm{FN}$ in the NL psoriatic skin are activated keratinocytes ${ }^{29}$. Another report on NL skin has showed that $\mathrm{EDA}^{+} \mathrm{FN}$ was localized mainly at the epidermal-dermal junction ${ }^{5}$. It is well established that $\alpha 5$ integrin and $\mathrm{EDA}^{+} \mathrm{FN}$ could play an important regulatory role in the abnormal epidermal homeostasis of psoriatic skin ${ }^{3,29}$, and more recent evidence suggests that $\mathrm{EDA}^{+} \mathrm{FN}$ could be crucial in activating immune cells ${ }^{30,31}$. The EDA motif encompasses two non-classical binding sites for $\alpha_{4} \beta_{1}$ and $\alpha_{9} \beta_{1}$ integrins ${ }^{32}$, receptors present on the surface of Tcells $^{33,34}$ that could enhance $\mathrm{T}$ cell migration and accumulation in $\mathrm{EDA}^{+} \mathrm{FN}$ containing tissues, such as the skin.

$\mathrm{EDA}^{+} \mathrm{FN}$ promotes acute inflammation and brain injury following cerebral ischemia in mice ${ }^{35}$. $\mathrm{EDA}^{+} \mathrm{FN}$ is normally absent in human plasma, however patients with chronic inflammation and ischemic stroke have high plasma $\mathrm{EDA}^{+} \mathrm{FN}$. The abnormally regulated overproduction of $\mathrm{EDA}^{+} \mathrm{FN}$ in psoriatic fibroblasts may be responsible not only for maintaining a local chronic inflammation in the skin, but by influencing plasma levels that could play a role in the systemic inflammation that is reported recently in psoriasis ${ }^{36}$. The $\mathrm{EDA}^{+} \mathrm{FN}$ rich extracellular milieu in the psoriatic skin could be crucial for maintaining the 
characteristic epidermal changes, as well as the chronic inflammation in psoriatic lesions (for review $\left.\operatorname{see}^{37,38}\right)$.

It has been reported that KGF stimulates EDA inclusion in a mouse mammary epithelial cell line $(\mathrm{SCp} 2)^{39}$. Although, the exact regulation of EDA ${ }^{+} \mathrm{FN}$ splicing is not completely clear, it is known that TGF- $\beta$ enhances $\mathrm{EDA}^{+} \mathrm{FN}$ production ${ }^{40}$. Our in silico model on KGF and FN signaling corroborate our experimental results in suggesting the participation of MEK1 in KGF induced fibronectin splicing through peptidyl-prolyl cis-trans isomerase (PPIG), a protein known to be important in protein folding and splicing ${ }^{20}$ and regulated by MEK1 induced AP-1.

Autocrine feedback of several different FGFs through FGFRs exists under both normal and pathological conditions ${ }^{16,19,41}$. KGF exerts its effect mainly through FGFR2-IIIb, but also via FGFR2-IIIc and FGFR $1^{17}$. Since both FGFR2 and FGFR1 can initiate MEK1 signaling, KGF could potentially modulate fibronectin splicing in a similar autocrine manner as other FGFs, most likely either through FGFR2-IIIc or FGFR1 ${ }^{16,42}$ in fibroblasts. However the participation other unknown receptors also cannot be excluded and further research is needed to understand the exact mechanism through which KGF affects FN splicing. Directly blocking $\mathrm{EDA}^{+} \mathrm{FN}$ seems less feasible as a therapeutic approach, as blocking KGF or its receptors ${ }^{43}$.

STAT1 is the founding member of the STAT (signal transducer and activator of transcription) family and it is activated by interferons (IFNs), and signaling from IL-27, IL-35 and TLRs ${ }^{44}$. There is ample evidence implicating IFN $\gamma$ in the pathomechanism of psoriasis ${ }^{45}$. Aberrant signaling and transcription have been reported for psoriatic keratinocytes with regard to SOCS1, a negative regulator of IFN $\gamma$ signaling ${ }^{46}$, and also for STAT1 and IRF-1 (interferon regulated factor 1$)^{47}$. The complex role of STAT1 in immune regulation is apparent from animal studies showing that both $\mathrm{STAT}^{-/-}$and $\mathrm{IFN} \gamma^{-/-}$mice are highly susceptible to experimental autoimmune encephalomyelitis $(\mathrm{EAE})^{48,49}$. It has been demonstrated that in both multiple sclerosis (MS) and in the EAE model $\alpha 5$ integrin and FN could be responsible for the extensive vascular remodelling, characteristic for MS, that takes place during the presymptomatic phase in $\mathrm{EAE}^{50}$. The regulatory connection between STAT1 and FN described in this paper may explain the more severe disease manifestation in $\mathrm{STAT}^{-/}$animals. STAT1 has diverse functions, it inhibits certain genes and it is a functional transcription factor even in the absence of inducer-mediated activation. Among its major targets of negative 
regulation are genes encoding proteins involved in regulating the extracellular matrix: matrix metalloproteinases (MMPs), perlecan, bullosus phemphigoid antigen-1 (BPAG1) ${ }^{51}$. As our results indicate, in normal homeostatic skin tissue a steady state of STAT1 activation is present and this could be partially responsible for downregulating $\mathrm{FN}$ and $\mathrm{EDA}^{+} \mathrm{FN}$ production, since blocking STAT1 in normal fibroblasts results in enhanced production of FN and $\mathrm{EDA}^{+} \mathrm{FN}$. The absent suppressive function of STAT1 in psoriatic fibroblasts could be crucial in the pathomechanism of psoriasis. Using a STAT1 decoy oligodeoxynucleotide (dODN)-containing ointment Wagner et al. were able to inhibit hapten-induced contact hypersensitivity reaction in animal models, indicating that topical STAT1 blockade could be a novel anti-inflammatory therapy in skin inflammation ${ }^{52}$. Our data indicate that in psoriasis STAT1 inactivation characterizes the uninvolved skin, thus, this type of therapy may well work as a symptomatic therapy for the lesional skin.

\section{Acknowledgements}

We are thankful to Mónika Kohajda for her assistance and we are also grateful to Róbertné Függ for the preparation of the biological samples. This study was supported by OTKA K83277, K105985, K111885, NK105369, PD116992 and by the European Union and the State of Hungary, co-financed by the European Social Fund in the framework of TÁMOP4.2.4.A/2-11-1/2012-0001 'National Excellence Program’ A2-SZGYA-FOK-13-0001. 


\section{References}

1 Bos JD, De Rie MA, Teunissen MB et al. Psoriasis: dysregulation of innate immunity. Br J Dermatol 2005; 152:1098-1107.

2 Pellegrini G, De Luca M, Orecchia G et al. Expression, topography, and function of integrin receptors are severely altered in keratinocytes from involved and uninvolved psoriatic skin. J Clin Invest 1992; 89:1783-1795.

3 Bata-Csorgo Z, Cooper KD, Ting KM et al. Fibronectin and alpha5 integrin regulate keratinocyte cell cycling. A mechanism for increased fibronectin potentiation of $\mathrm{T}$ cell lymphokine-driven keratinocyte hyperproliferation in psoriasis. J Clin Invest 1998; 101:1509-1518.

4 Carroll JM, Romero MR, Watt FM. Suprabasal integrin expression in the epidermis of transgenic mice results in developmental defects and a phenotype resembling psoriasis. Cell 1995; 83:957-968.

5 Ting KM, Rothaupt D, McCormick TS et al. Overexpression of the oncofetal Fn variant containing the EDA splice-in segment in the dermal-epidermal junction of psoriatic uninvolved skin. $J$ Invest Dermatol 2000; 114:706-711.

6 Guo L, Yu QC, Fuchs E. Targeting expression of keratinocyte growth factor to keratinocytes elicits striking changes in epithelial differentiation in transgenic mice. EMBO J 1993; 12:973-986.

7 Krueger GG, Jorgensen CM. Experimental models for psoriasis. J Invest Dermatol 1990; 95:56S-58S.

8 Andreadis ST, Hamoen KE, Yarmush ML et al. Keratinocyte growth factor induces hyperproliferation and delays differentiation in a skin equivalent model system. FASEB J 2001; 15:898-906.

9 Zhang X, Ibrahimi OA, Olsen SK et al. Receptor specificity of the fibroblast growth factor family. The complete mammalian FGF family. J Biol Chem 2006; 281:1569415700 .

10 Kormos B, Belso N, Bebes A et al. In vitro dedifferentiation of melanocytes from adult epidermis. PLoS ONE 2011; 6:e17197.

11 Uzan B, Figeac F, Portha B et al. Mechanisms of KGF mediated signaling in pancreatic duct cell proliferation and differentiation. PLOS ONE 2009; 4:e4734.

12 Cichon AC, Pickard A, McDade SS et al. AKT in stromal fibroblasts controls invasion of epithelial cells. Oncotarget 2013; 4:1103-1116.

13 Huang R, Faratian D, Sims AH et al. Increased STAT1 signaling in endocrine-resistant breast cancer. PLOS ONE 2014; 9:e94226. 
14 Khan ZA, Cukiernik M, Gonder JR et al. Oncofetal fibronectin in diabetic retinopathy. Invest Ophthalmol Vis Sci 2004; 45:287-295.

15 D'Amici S, Ceccarelli S, Vescarelli E et al. TNFalpha modulates Fibroblast Growth Factor Receptor 2 gene expression through the pRB/E2F1 pathway: identification of a non-canonical E2F binding motif. PLoS ONE 2013; 8:e61491.

16 Powers CJ, McLeskey SW, Wellstein A. Fibroblast growth factors, their receptors and signaling. Endocr Relat Cancer 2000; 7:165-197.

17 Ornitz DM, Xu J, Colvin JS et al. Receptor specificity of the fibroblast growth factor family. J Biol Chem 1996; 271:15292-15297.

18 Eswarakumar VP, Lax I, Schlessinger J. Cellular signaling by fibroblast growth factor receptors. Cytokine Growth Factor Rev 2005; 16:139-149.

19 Turner N, Grose R. Fibroblast growth factor signalling: from development to cancer. Nat Rev Cancer 2010; 10:116-129.

20 Bourquin JP, Stagljar I, Meier P et al. A serine/arginine-rich nuclear matrix cyclophilin interacts with the C-terminal domain of RNA polymerase II. Nucleic Acids Res 1997; 25:2055-2061.

21 Finch PW, Murphy F, Cardinale I et al. Altered expression of keratinocyte growth factor and its receptor in psoriasis. Am J Pathol 1997; 151:1619-1628.

22 Kovacs D, Falchi M, Cardinali G et al. Immunohistochemical analysis of keratinocyte growth factor and fibroblast growth factor 10 expression in psoriasis. Exp Dermatol $2005 ; 14: 130-137$.

23 Haimes E. Issues of gender in gamete donation. Soc Sci Med 1993; 36:85-93.

24 Tang A, Gilchrest BA. Regulation of keratinocyte growth factor gene expression in human skin fibroblasts. J Dermatol Sci 1996; 11:41-50.

25 Maas-Szabowski N, Shimotoyodome A, Fusenig NE. Keratinocyte growth regulation in fibroblast cocultures via a double paracrine mechanism. J Cell Sci 1999; 112 ( Pt 12):1843-1853.

26 Szabowski A, Maas-Szabowski N, Andrecht S et al. c-Jun and JunB antagonistically control cytokine-regulated mesenchymal-epidermal interaction in skin. Cell 2000; 103:745-755.

$27 \mathrm{Xu} \mathrm{N}$, Brodin P, Wei $\mathrm{T}$ et al. MiR-125b, a microRNA downregulated in psoriasis, modulates keratinocyte proliferation by targeting FGFR2. J Invest Dermatol 2011; 131:1521-1529.

28 Avraamides CJ, Garmy-Susini B, Varner JA. Integrins in angiogenesis and lymphangiogenesis. Nat Rev Cancer 2008; 8:604-617. 
29 Szell M, Bata-Csorgo Z, Koreck A et al. Proliferating Keratinocytes Are Putative Sources of the Psoriasis Susceptibility-Related EDA (Extra Domain A of Fibronectin) Oncofetal Fibronectin. J Invest Dermatol 2004; 123:537-546.

30 Okamura Y, Watari M, Jerud ES et al. The extra domain A of fibronectin activates Tolllike receptor 4. J Biol Chem 2001; 276:10229-10233.

31 Sandig H, McDonald J, Gilmour J et al. Fibronectin is a TH1-specific molecule in human subjects. J Allergy Clin Immunol 2009; 124:528-35, 535.

32 White ES, Baralle FE, Muro AF. New insights into form and function of fibronectin splice variants. $J$ Pathol 2008; 216:1-14.

33 Kanayama M, Morimoto J, Matsui $\mathrm{Y}$ et al. alpha9beta1 integrin-mediated signaling serves as an intrinsic regulator of pathogenic Th17 cell generation. J Immunol 2011; 187:5851-5864.

34 Brown WS, Khalili JS, Rodriguez-Cruz TG et al. B-Raf regulation of integrin alpha4beta1-mediated resistance to shear stress through changes in cell spreading and cytoskeletal association in T cells. J Biol Chem 2014; 289:23141-23153.

35 Khan MM, Gandhi C, Chauhan N et al. Alternatively-spliced extra domain A of fibronectin promotes acute inflammation and brain injury after cerebral ischemia in mice. Stroke 2012; 43:1376-1382.

36 Shlyankevich J, Mehta NN, Krueger JG et al. Accumulating evidence for the association and shared pathogenic mechanisms between psoriasis and cardiovascular-related comorbidities. Am J Med 2014; 127:1148-1153.

37 McFadden JP, Baker BS, Powles AV et al. Psoriasis and extra domain A fibronectin loops. Br J Dermatol 2010; 163:5-11.

38 McFadden J, Fry L, Powles AV et al. Concepts in psoriasis: psoriasis and the extracellular matrix. Br J Dermatol 2012; 167:980-986.

39 Blaustein M, Pelisch F, Coso OA et al. Mammary epithelial-mesenchymal interaction regulates fibronectin alternative splicing via phosphatidylinositol 3-kinase. J Biol Chem 2004; 279:21029-21037.

40 Baelde HJ, Eikmans M, van Vliet AI et al. Alternatively spliced isoforms of fibronectin in immune-mediated glomerulosclerosis: the role of TGFbeta and IL-4. J Pathol 2004; 204:248-257.

41 Strutz F, Zeisberg M, Hemmerlein B et al. Basic fibroblast growth factor expression is increased in human renal fibrogenesis and may mediate autocrine fibroblast proliferation. Kidney Int 2000; 57:1521-1538.

42 Murakami M, Elfenbein A, Simons M. Non-canonical fibroblast growth factor signalling in angiogenesis. Cardiovasc Res 2008; 78:223-231.

43 Jarvelainen H, Sainio A, Koulu M et al. Extracellular matrix molecules: potential targets in pharmacotherapy. Pharmacol Rev 2009; 61:198-223. 
44 Luu K, Greenhill CJ, Majoros A et al. STAT1 plays a role in TLR signal transduction and inflammatory responses. Immunol Cell Biol 2014; 92:761-769.

45 Bata-Csorgo Z, Szell M. The psoriatic keratinocytes. Expert Rev Dermatol 2012; 7:473-481.

46 Madonna S, Scarponi C, Sestito R et al. The IFN-gamma-dependent suppressor of cytokine signaling 1 promoter activity is positively regulated by IFN regulatory factor-1 and $\mathrm{Sp} 1$ but repressed by growth factor independence- $1 \mathrm{~b}$ and Kruppel-like factor-4, and it is dysregulated in psoriatic keratinocytes. J Immunol 2010; 185:2467-2481.

47 McKenzie RC, Sabin E. Aberrant signalling and transcription factor activation as an explanation for the defective growth control and differentiation of keratinocytes in psoriasis: a hypothesis. Exp Dermatol 2003; 12:337-345.

48 Bettelli E, Sullivan B, Szabo SJ et al. Loss of T-bet, but not STAT1, prevents the development of experimental autoimmune encephalomyelitis. $J$ Exp Med 2004; 200:79-87.

49 Prinz M, Schmidt H, Mildner A et al. Distinct and nonredundant in vivo functions of IFNAR on myeloid cells limit autoimmunity in the central nervous system. Immunity 2008; 28:675-686.

50 Boroujerdi A, Welser-Alves JV, Milner R. Extensive vascular remodeling in the spinal cord of pre-symptomatic experimental autoimmune encephalomyelitis mice; increased vessel expression of fibronectin and the alpha5betal integrin. Exp Neurol 2013; 250:43-51.

51 Ramana CV, Chatterjee-Kishore $\mathrm{M}$, Nguyen $\mathrm{H}$ et al. Complex roles of Stat1 in regulating gene expression. Oncogene 2000; 19:2619-2627.

52 Wagner AH, Wittjen I, Stojanovic $\mathrm{T}$ et al. Signal transducer and activator of transcription 1 decoy oligodeoxynucleotide suppression of contact hypersensitivity. $J$ Allergy Clin Immunol 2008; 121:158-165. 
Figure legend

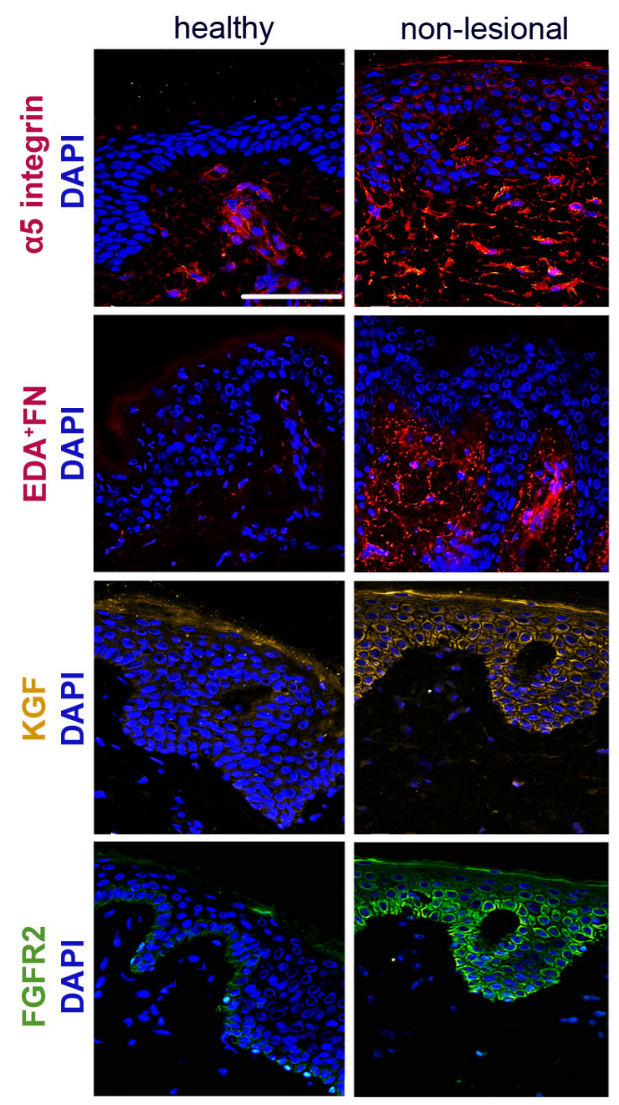

Figure 1. Increased expression of $\alpha_{5}$ integrin, $\mathrm{EDA}^{+} \mathrm{FN}, \mathrm{KGF}$ and FGFR2 in non-lesional skin without mechanical stress stimuli. Immunofluorescent analysis of $\alpha_{5}$ integrin, $\mathrm{EDA}^{+} \mathrm{FN}, \mathrm{KGF}$ and FGFR2 in healthy (upper row) and non-lesional skin (lower row) $(n=6)$. Bar: $50 \mu \mathrm{m}$ 
a
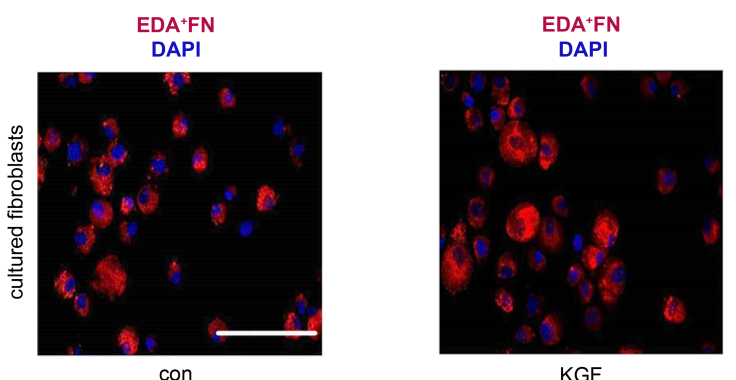

b
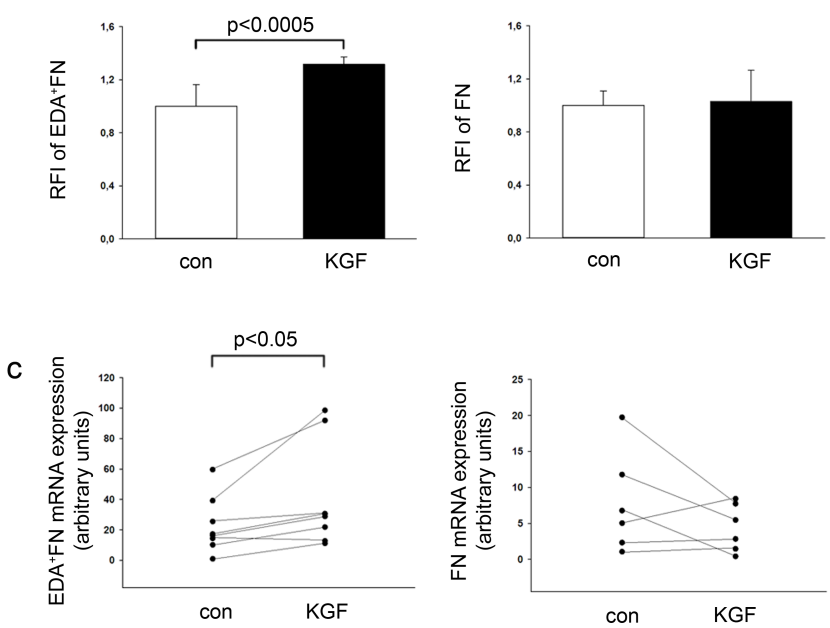

Figure 2. The expression of $\mathrm{EDA}^{+} \mathrm{FN}$ is induced by KGF in normal human fibroblasts.

KGF treated fibroblasts and the change in expression in $\mathrm{FN}$ and $\mathrm{EDA}^{+} \mathrm{FN}$ at 24 hours. a) Immunofluorescent detection of EDA ${ }^{+} F N$. b) Flow cytometry measurement of EDA ${ }^{+} F N$ and FN levels following KGF treatment. RFI: relative fluorescence intensity. c) FN or EDA $\mathrm{FN}^{+}$ mRNA expression following KGF stimulation. Values are expressed in arbitrary units. Data represent the mean \pm SEM ( $\mathrm{n}=6)$. Bar: $50 \mu \mathrm{m}$. 
a

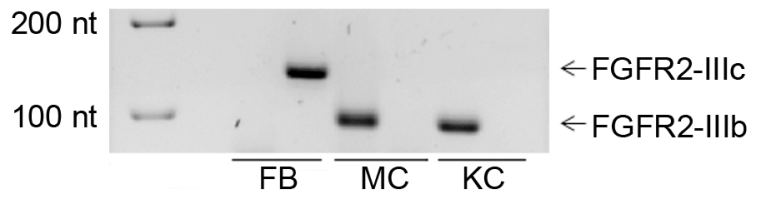

b

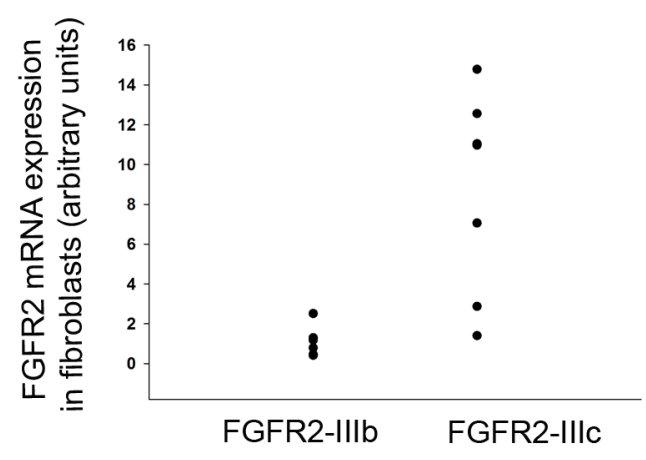

Figure 3. Human fibroblasts in culture mainly express the FGFR2-IIIc while melanocytes and keratinocytes the FGFR2-IIIb splice variant of FGFR2. a) RT-PCR products specific for FGFR2-IIIb and -IIIc were run on a $2 \%$ agarose gel of cultured human fibroblasts (FB), melanocytes (MC) and keratinocytes (KC). b) FGFR2 mRNA expression by fibroblasts for the two investigated splice variants detected by real-time RT-PCR. Values are expressed in arbitrary units. 
a

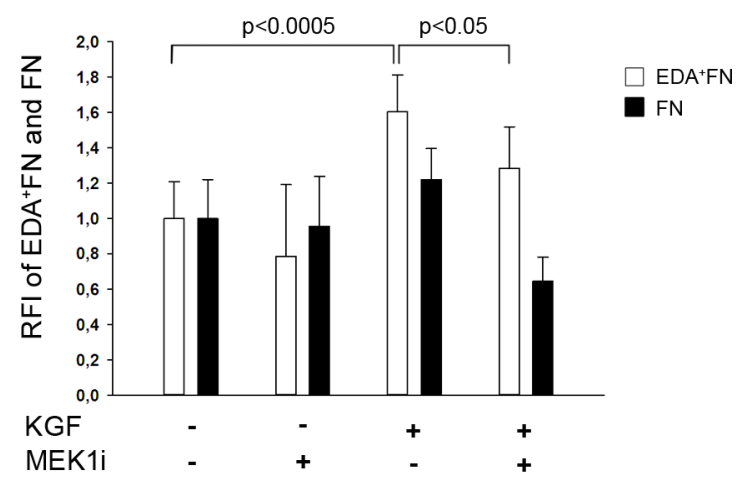

b

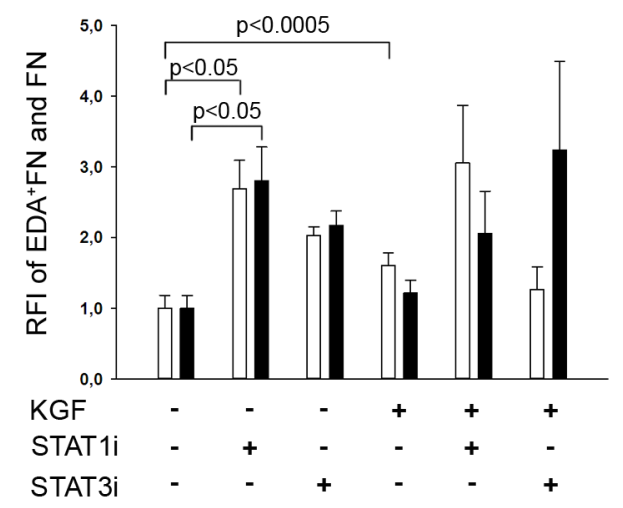

C

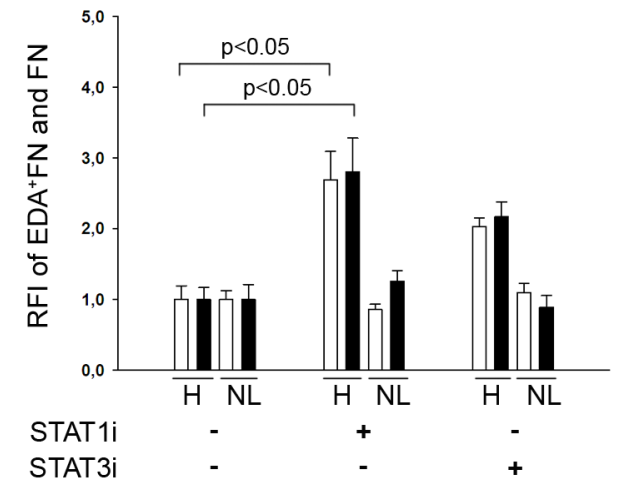

d

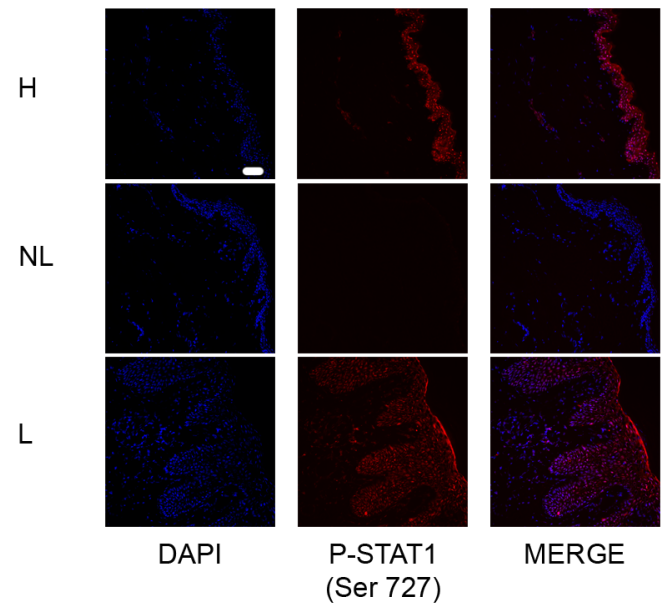

Figure 4. KGF influenced elevation of the $\operatorname{EDA}^{+} \mathrm{FN}$ is mediated through MAPK signaling and altered STAT1 regulation of $\mathrm{EDA}^{+} \mathrm{FN}$ and $\mathrm{FN}$ expression in psoriasis. a) 
FN and EDA ${ }^{+} \mathrm{FN}$ levels of healthy fibroblasts treated with KGF alone or in combination with MEK1 inhibitor. b) Following treatment of healthy fibroblasts with KGF alone or in combination with inhibitors for STAT1, STAT3 or both. c) The effect of STAT1 and STAT3 inhibition on $\mathrm{FN}$ and $\mathrm{EDA}^{+} \mathrm{FN}$ in healthy and non-lesional skin derived fibroblasts. d) Immunofluorescent analysis of STAT1 Ser727 phosphorylation. H: healthy, NL: non-lesional, and L: lesional skin. Data represent the mean \pm SEM $(n=6)$. RFI: relative fluorescence intensity. Bar: $50 \mu \mathrm{m}$.

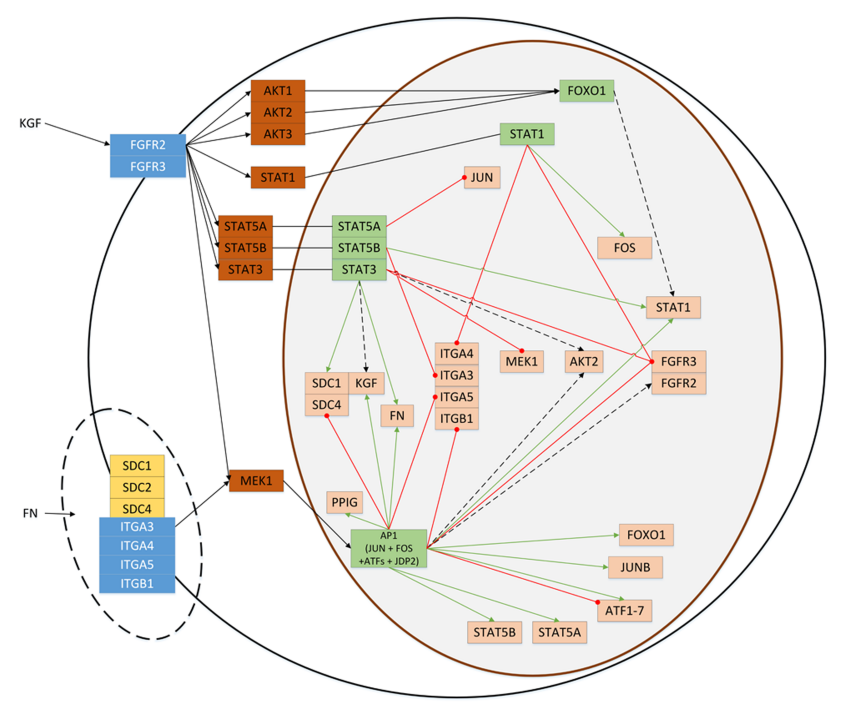

Figure 5. In silico model of KGF and FN signaling. Green arrow: positive transcriptional regulation; Red arrow with circle arrowhead: negative transcriptional regulation; Arrows with dashed lines: undetermined direction of regulation. 


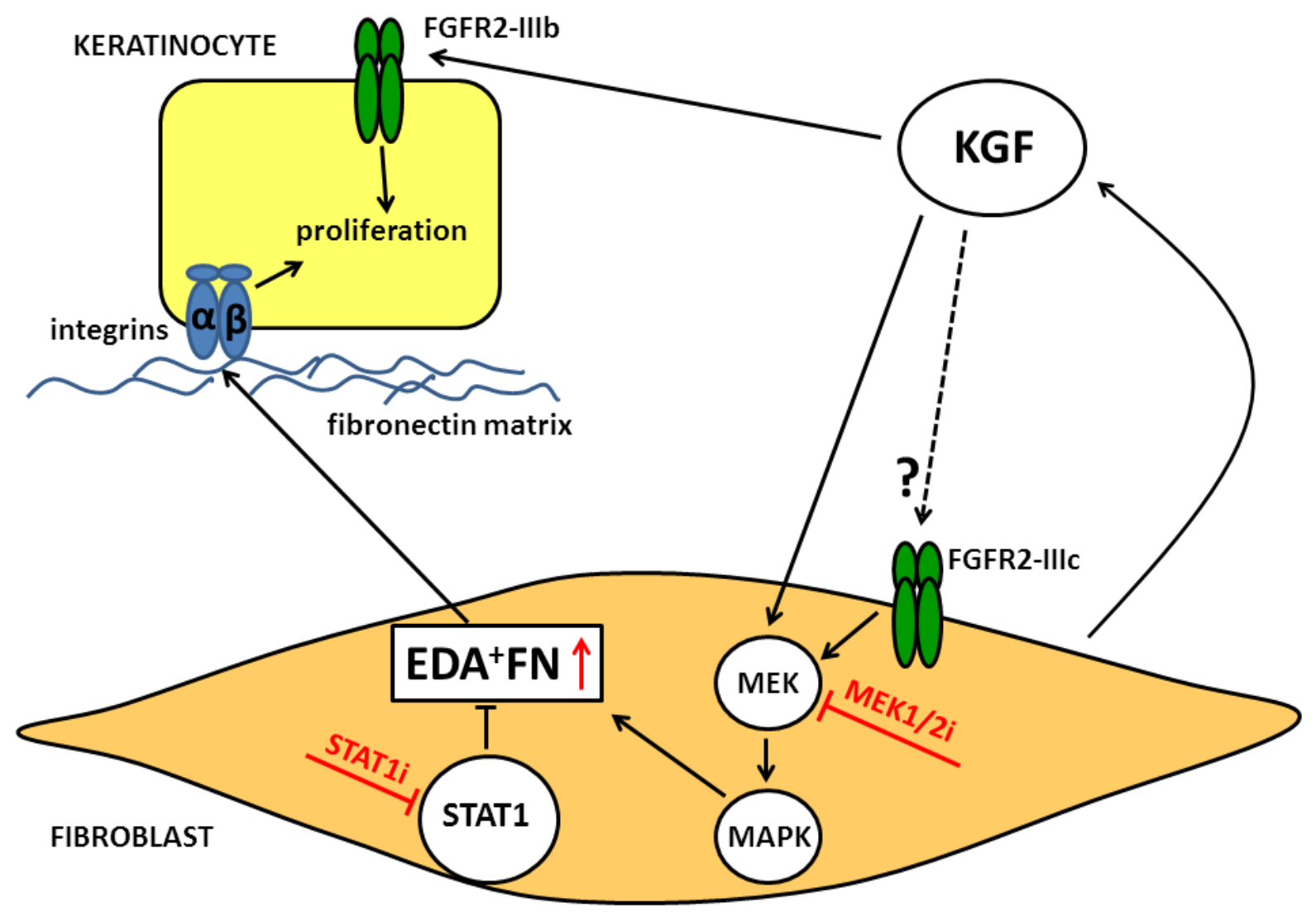

Figure 6. Schematic model of investigated molecules playing a role in KGF mediated EDA $^{+} \mathrm{FN}$ production in healthy skin. 


\section{Supplementary materials and methods}

\section{Cell culture}

Primary keratinocytes, melanocytes and fibroblasts were obtained from healthy participants or psoriatic patients by enzymatic digestion of skin biopsies according to a standard protocol. Briefly skin specimens were first washed in Salsol A solution (Human Rt, Gödöllö, Hungary) supplemented with $2 \%$ antibiotic/antimycotic solution (Sigma-Aldrich). Skin samples were then cut into narrow strips and incubated in Dispase solution (Roche Diagnostics, Mannheim, Germany) overnight at $4^{\circ} \mathrm{C}$. The epidermis was subsequently separated from the dermis and incubated in $0.25 \%$ trypsin $/ 0.02 \%$ EDTA (PAA, Pasching, Austria) for 5 min at $37^{\circ} \mathrm{C}$ to achieve a single-cell epidermal suspension. Fibroblasts were obtained by incubating the dermis in Digestion Mix (Collagenase, Hyaluronidase and Deoxyribonuclease) for $2 \mathrm{~h}$ at $37^{\circ} \mathrm{C}$. The cell suspensions were filtered through a $100 \mu$ m nylon mesh (BD Falcon, San Jose, CA, USA) and pelleted by centrifugation.

Fibroblasts were grown in low glucose DMEM medium containing 5\% FBS. Melanocytes were maintained in Mel-mix medium as previously described ${ }^{10}$. Keratinocytes were grown in keratinocyte serum-free medium (Gibco ${ }^{\circledR}$ Keratinocyte SFM Kit; Life Technologies, Copenhagen, Denmark). HaCaT cells were kindly provided by Prof N.E. Fusenig and cultured in high-glucose DMEM medium containing 10\% FBS. All media was supplemented with 1\% antibiotic/antimycotic (PAA) and 1\% L-glutamine solution (PAA). Fibroblasts, keratinocytes, melanocytes, and $\mathrm{HaCaT}$ cells were cultured at $37^{\circ} \mathrm{C}$ and $5 \% \mathrm{CO}_{2}$ in humidified conditions. Depending on the cell growth, the medium was changed every 2-4 days and cells were passaged at $80 \%$ confluence. In our experiments, fibroblasts at passage number 5, keratinocytes and melanocytes at passage 3 were used at $70 \%$ confluence.

Fibroblasts, keratinocytes and $\mathrm{HaCaT}$ cells were cultured in 6-well plates at a starting density of 200,000 cells/well and incubated with 25 ng/mL KGF (ProSpec -Tany TechnoGene Ltd., Rehovot, Israel) for $24 \mathrm{~h}$; untreated cells were used as controls. For KGF signaling pathway blocking experiments the following inhibitors were used: MEK1 inhibitor (PD98059, 20 $\mu \mathrm{M}$ ), Akt $1 / 2$ kinase inhibitor $(10 \mu \mathrm{M})$, STAT1 inhibitor (Epigallocatechin gallate, $40 \mu \mathrm{M}$ ) and STAT3 inhibitor (Stattic, $4 \mu \mathrm{M}$ ), all provided by Sigma-Aldrich, concentrations were applied as previously described ${ }^{11-13}$. 


\section{RNA extraction and real-time quantitative reverse transcription polymerase chain reaction (RT qRT-PCR)}

For RNA isolation fibroblasts, melanocytes and keratinocytes were cultured as described above. Cells on 6 well plates were washed once with PBS, then harvested with $0.5 \mathrm{ml}$ TRIzol $^{\mathrm{TM}}$ Reagent (Life Technologies). Total RNA was isolated according to the manufacturer's instructions. RNA concentration was determined from A260 values. All RNA was treated with DNA-free ${ }^{\mathrm{TM}}$ reagents (Life Technologies). cDNA was synthesized from $1 \mu \mathrm{g}$ total RNA with the iScript cDNA Synthesis Kit (Bio-Rad Laboratories, Hercules, CA, USA) according to the manufacturer's protocol.

For EDA ${ }^{+}$FN qPCR amplification $\mathrm{iQ}^{\mathrm{TM}}$ Supermix (from Bio-Rad Laboratories Hercules, CA, USA) was used. The $\mathrm{EDA}^{+} \mathrm{FN}$ primers were constructed as described previously ${ }^{14}$. The amplification protocol for $\mathrm{EDA}^{+} \mathrm{FN}$ qPCR was the following: $95^{\circ} \mathrm{C}$ for $3 \mathrm{~min}$, and then $95^{\circ} \mathrm{C}$ for $15 \mathrm{~s}$ and $56^{\circ} \mathrm{C}$ for $30 \mathrm{~s}$, repeated 40 times.

FN1 and 18S amplifications were carried out with FastStart TaqMan Probe Mastermix (Roche Basel, Switzerland) using the following primers: FN1 forward 5'GGAAAGTGTCCCTATCTCTGATACC-3', reverse 5'-AATGTTGGTGAATCGCAGGT3', probe: \#33. 18S RNA forward 5'-CTCAACACGGGAAACCTCAC-3', reverse 5'CGCTCCACCAACTAAGAACG-3', probe: \#77 (probes were from the Roche Universal Probe Library). Primers were designed using Probefinder for the Universal Probe Library system (Roche Diagnostics, Basel, Switzerland). FN1 and 18SrRNA amplifications were carried out under the following conditions: $95^{\circ} \mathrm{C}$ for $3 \mathrm{~min}$, and then $95^{\circ} \mathrm{C}$ for $15 \mathrm{~s}$ and $57^{\circ} \mathrm{C}$ for $1 \mathrm{~min}$, repeated 40 times.

For FGFR2-IIIb and FGFR2-IIIc, specific custom TaqMan primer/probe sets (Life Technologies, Carlsbad, CA, USA) were developed as described previously ${ }^{15}$ and for amplification the following protocol was used: $95^{\circ} \mathrm{C}$ for $10 \mathrm{~min}$, and then $95^{\circ} \mathrm{C}$ for $15 \mathrm{~s}$ and $60^{\circ} \mathrm{C}$ for $1 \mathrm{~min}$, repeated 40 times.

RT-PCR experiments were carried out on the LightCycler ${ }^{\circledR} 480$ System Real-Time PCR machine (Roche Cobas Z 480 Roche Diagnostics). The abundance of each gene products was normalized to the $18 \mathrm{~S}$ rRNA gene expression in each examined sample. Relative mRNA levels were calculated by the $2^{-\Delta \Delta \mathrm{Ct}}$ method. Data are expressed as arbitrary units proportional to the mRNA level. 


\section{Bioinformatics analysis and model construction}

STRING, KEGG database and Reactome were used as a source to create protein-protein interactions and signaling pathways; SABiosciences' transcription factor binding site data and CisRED $(p<0.001)$ were applied for modeling protein-DNA interactions. Direction of transcriptional regulation was assessed with expression correlation matrix. Data of a microarray study with 48 dermal fibroblast samples carried out by Gabig-Cimińska et al. was downloaded from Gene Expression Omnibus. Probe with the largest interquartile range (IQR) was selected for genes with multiple probes. Coexpressional matrix was constructed using MATLAB R2014b (MathWorks Inc., Natick, MA). The genes and proteins related to KGF signaling, fibronectin-signaling, splicing and the regulation of these genes were collected (summarized in Supplementary Table 1.) and used for filtered matrix construction (Supplementary Table 2.). We used Pearson correlation coefficients with $\mathrm{p}$ values under 0.05 for the assessment of the direction of transcriptional regulation. If correlation coefficient was positive it was considered an upregulation, and if it was negative, down regulation was defined. 
a

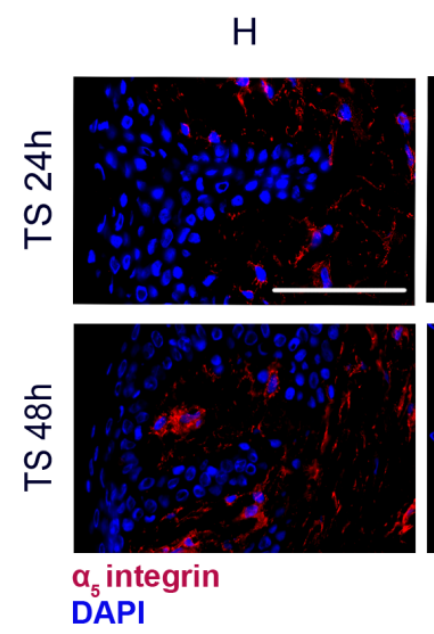

C

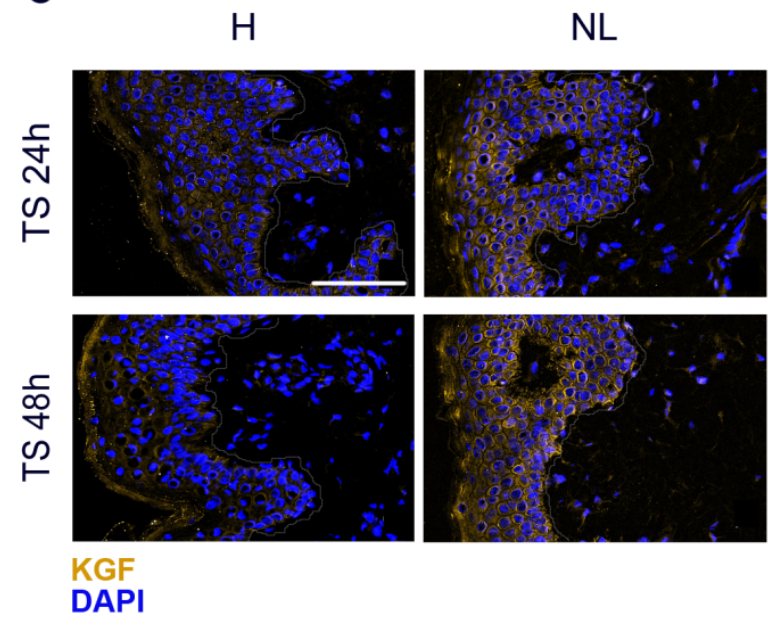

$\mathrm{NL}$
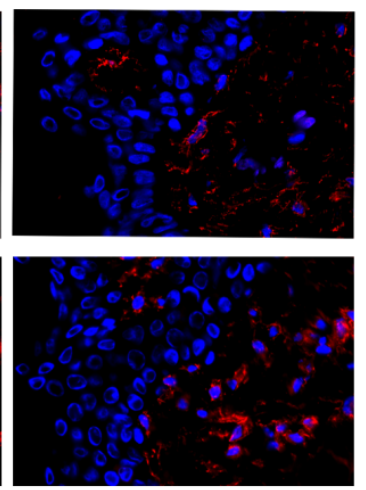

DAPI

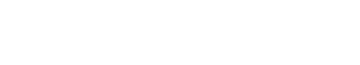

DAPI b

d
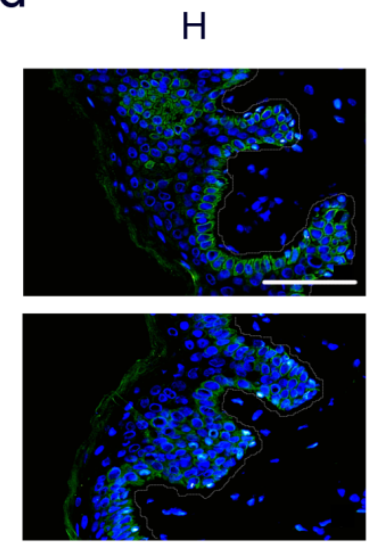

FGFR2

DAPI

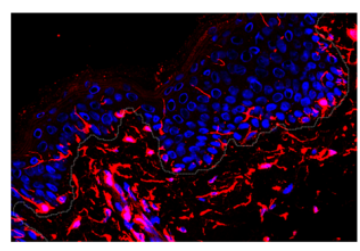

$\mathrm{NL}$
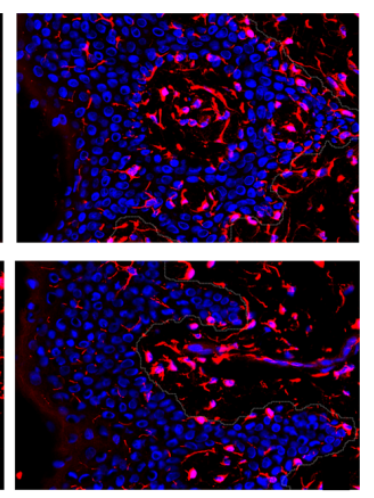

EDA+FN

DAPI

$\mathrm{H}$
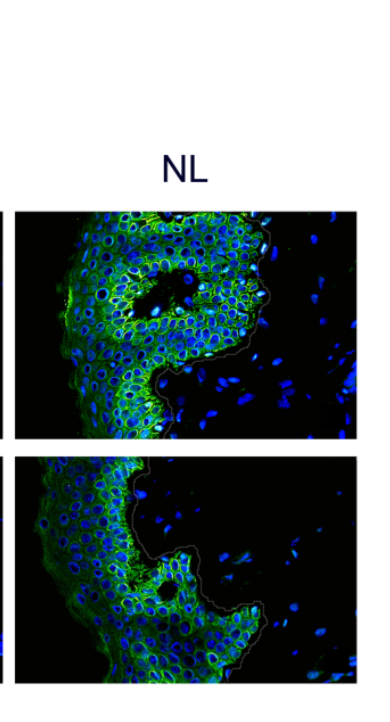

Supplementary figure 1. Mild mechanical stress induced by tape stripping has no effect on the expression of $\alpha_{5}$ integrin, EDA ${ }^{+}$FN, KGF or FGFR2 in non-lesional psoriatic skin and only a mild effect on healthy skin. The protein expression of $\alpha_{5}$ integrin (a), EDA ${ }^{+} \mathrm{FN}$ (b), KGF (c) and FGFR2 (d) was visualized by immunofluorescent staining 24 and 48 hours following tape stripping in healthy and in non-lesional skin. Bar: $50 \mu \mathrm{m}$. 
a
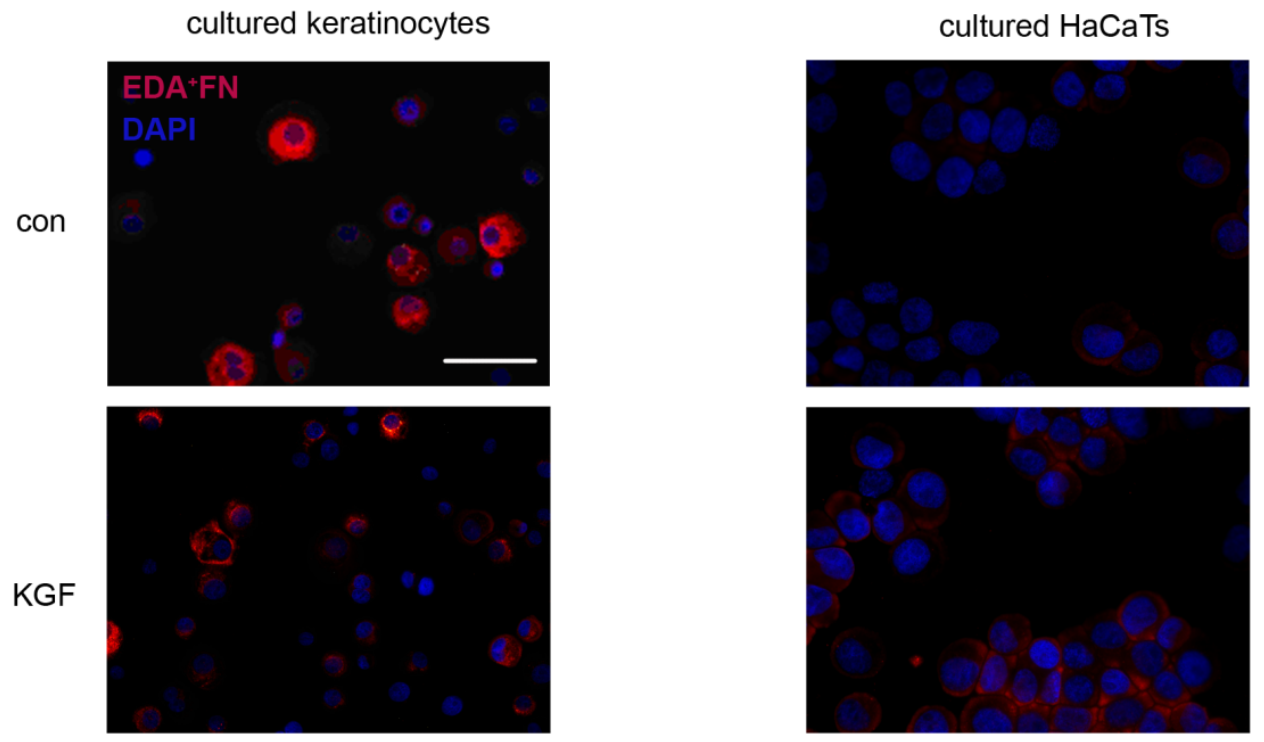

b
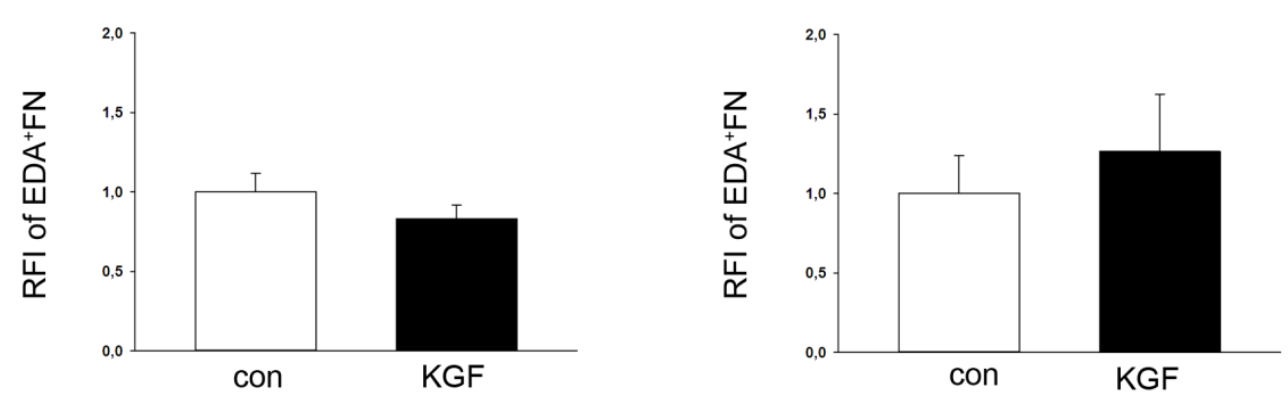

C
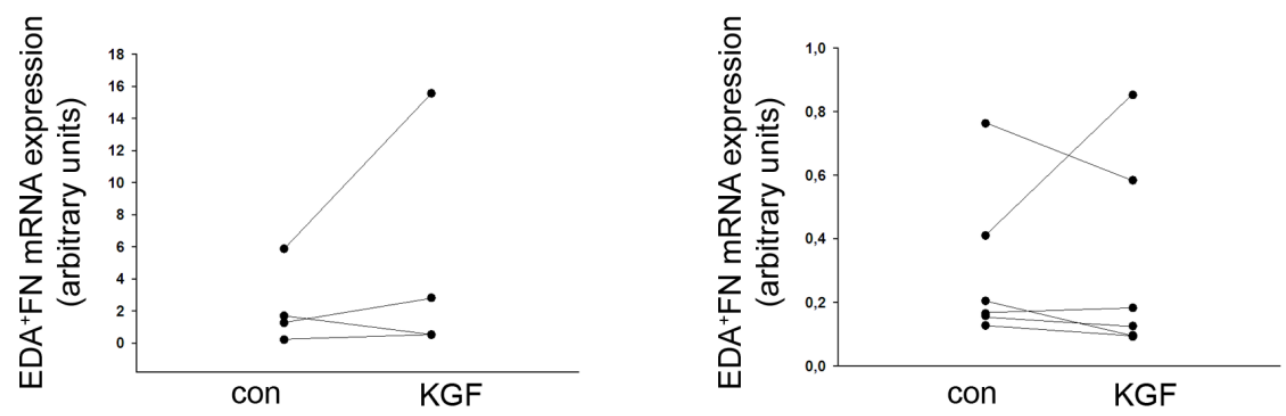

Supplementary figure 2. Exogenous KGF treatment has no effect on $\operatorname{EDA}^{+} \mathrm{FN}$ expression of keratinocytes and $\mathrm{HaCaT}$ cells. The expression of $\mathrm{EDA}^{+} \mathrm{FN}$ was visualized by immunostaining (a), its protein amount was quantified by flow cytometry (b) and mRNA expression was determined by real-time RT-PCR measurements (c) following 24 hours of 25 $\mathrm{ng} / \mathrm{ml} \mathrm{KGF}$ treatment of healthy human keratinocytes and $\mathrm{HaCaT}$ cells. RFI: relative fluorescence intensity. Values are expressed in arbitrary units. Bar: $50 \mu \mathrm{m}$. 


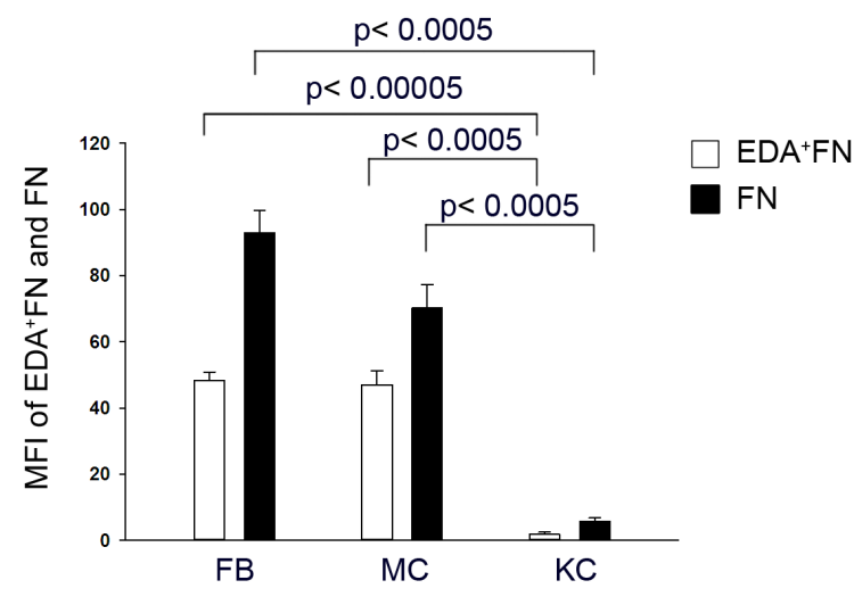

Supplementary figure 3. Fibroblast and melanocytes show higher expression of $\mathrm{EDA}^{+} \mathrm{FN}$ and FN than keratinocytes. The expression of EDA ${ }^{+} \mathrm{FN}$ and FN was compared among healthy fibroblasts, melanocytes and keratinocytes by flow cytometry 24 hours following plating measured by flow cytometry. MFI: mean fluorescence intensity. 


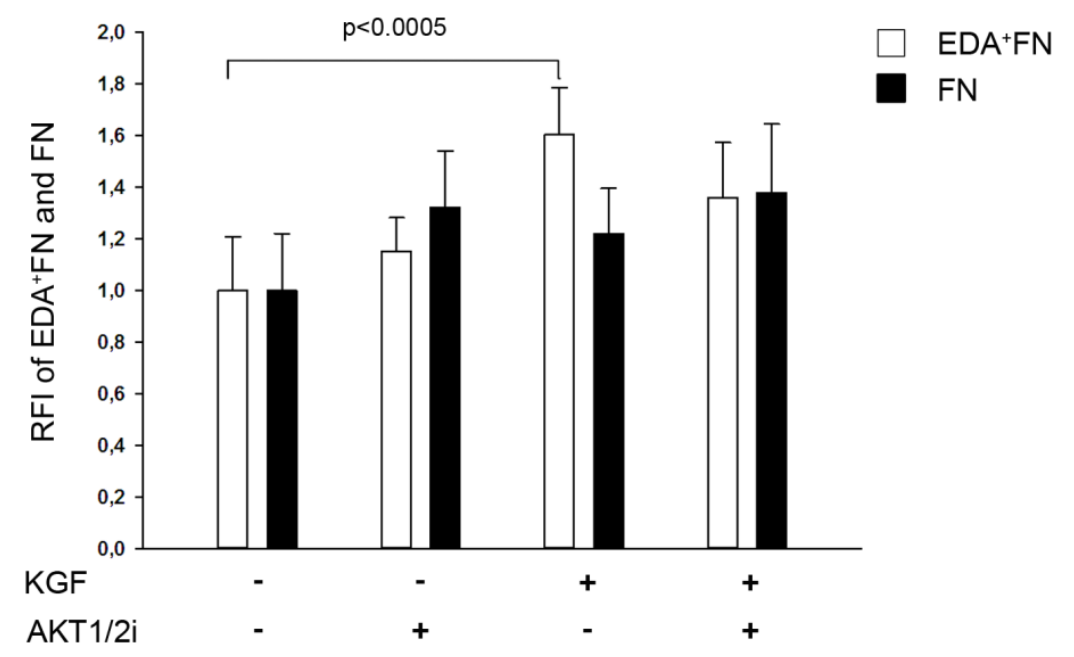

Supplementary figure 4. Exogenous KGF treatment triggered increase of $\mathrm{EDA}^{+} \mathrm{FN}$ and FN is not influenced by Akt1/2 inhibition. The level of fibroblasts produced $\mathrm{EDA}^{+} \mathrm{FN}$ and FN was measured by flow cytometry following $24 \mathrm{~h}$ of KGF incubation with or without Akt1/2 inhibitor. Cells untreated with KGF or treated alone with the Akt1/2 inhibitor were used as controls. RFI: relative fluorescence intensity.

Supplementary Table 1. List of genes applied for the construction of the co-expression matrix gene model.

Supplementary Table 2. Co-expression matrix of genes in our model Red bold characters indicate correlation coefficients with $\mathrm{p}<0.05$ between transcription factors and known targets. Red-shaded cells show positive correlation, blue shaded cells show negative correlation. Shade marks with the strength of correlation. Cells with thick margin means that there is binding site of the given transcription factor in the promoter region of the target gene. 